\title{
Second Annual Progress Report on Ultrasonic Sensors for TREAT Fuel Condition Measurement and Monitoring
}

\author{
Joshua Daw, Lance Hone-INL \\ Andrew Casella, Matthew Prowant, Chris \\ Hutchinson, Morris Good, Robert \\ Montgomery-PNNL \\ Pradeep Ramuhalli-ORNL \\ November 2019
}

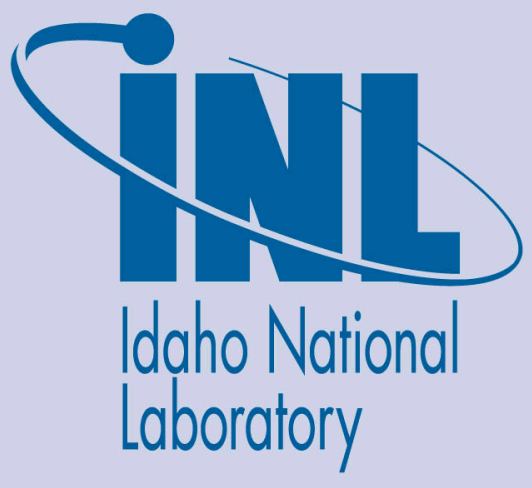




\section{DISCLAIMER}

This information was prepared as an account of work sponsored by an agency of the U.S. Government. Neither the U.S. Government nor any agency thereof, nor any of their employees, makes any warranty, expressed or implied, or assumes any legal liability or responsibility for the accuracy, completeness, or usefulness, of any information, apparatus, product, or process disclosed, or represents that its use would not infringe privately owned rights. References herein to any specific commercial product, process, or service by trade name, trade mark, manufacturer, or otherwise, does not necessarily constitute or imply its endorsement, recommendation, or favoring by the U.S. Government or any agency thereof. The views and opinions of authors expressed herein do not necessarily state or reflect those of the U.S. Government or any agency theof. 


\title{
Second Annual Progress Report on Ultrasonic Sensors for TREAT Fuel Condition Measurement and Monitoring
}

\author{
Joshua Daw, Lance Hone-INL \\ Andrew Casella, Matthew Prowant, Chris Hutchinson, Morris Good, Robert \\ Montgomery-PNNL \\ Pradeep Ramuhalli-ORNL
}

November 2019

Idaho National Laboratory

Pacific Northwest National Laboratory

Idaho Falls, Idaho 83415

http://www.inl.gov

Prepared for the

U.S. Department of Energy

Office of

Under DOE Idaho Operations Office

Contract DE-AC07-05ID14517 


\title{
Second Annual Progress Report on Ultrasonic Sensors for TREAT Fuel Condition Measurement and Monitoring
}

\author{
INL/EXT-19- 56006 \\ Revision 0 \\ November 2019
}

Approved by:

Name

Title [optional]

Name

Title [optional]

Name

Title [optional]

Name

Title [optional]
Date

Date
Date 



\begin{abstract}
Fuel deformation (both axial and radial) information provides insights into fuel performance and failure limits. Traditionally, fuel deformation has been quantified using post-irradiation examinations due to the lack of an appropriate sensor for monitoring deformation in situ. Recent developments in sensor and instrumentation design have led to the use of linear variable differential transformers (LVDT) for monitoring axial strain in fuel during irradiation. Size and operational constraints limit the use of LVDT sensors for radial deformation monitoring, and alternatives are needed.

One possible alternative to LVDT sensors is an ultrasonic sensor. Ultrasonic sensors monitor the interaction of high-frequency stress waves with the test object. The resulting response may be analyzed to determine the properties of the material, including stress, strain, microstructure, presence of defects, and the elastic constants. While ultrasonic measurements have been successfully applied for monitoring strain in a number of applications, their use for in-core measurements has been limited. Largely, the limitations are due to the challenges associated with designing sensors that can operate under typical in-core conditions.
\end{abstract}

The overall objective of this work is to design an ultrasonic sensor capable of rapid in-situ measurements of fuel rodlet dimensional changes during TREAT transient irradiation testing. This report summarizes the activities and research findings through the end of Year 2 of this three-year project. 


\section{CONTENTS}



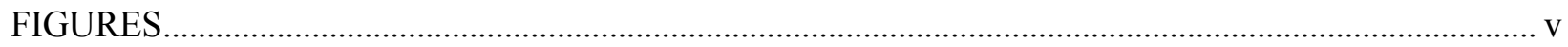

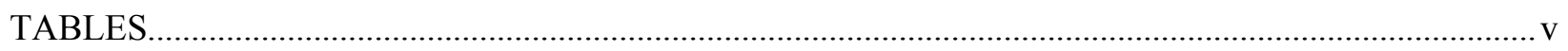

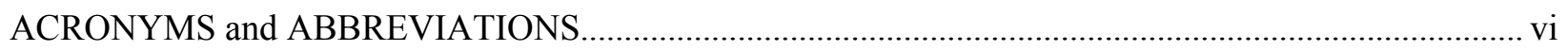

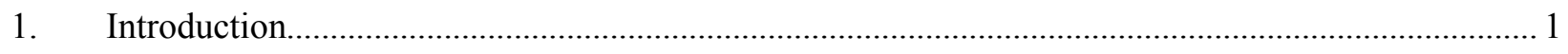

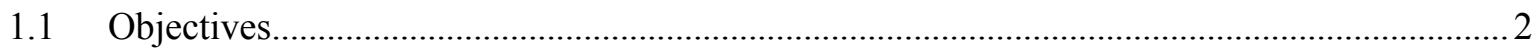

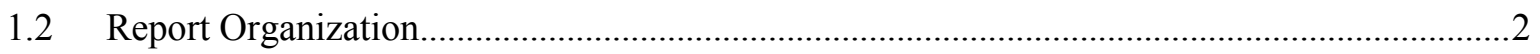

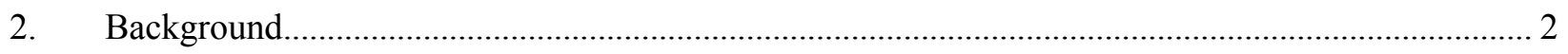

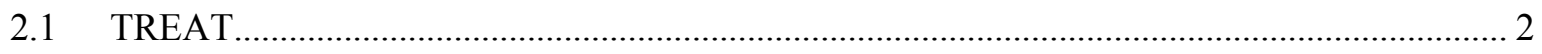

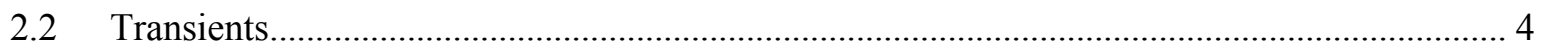

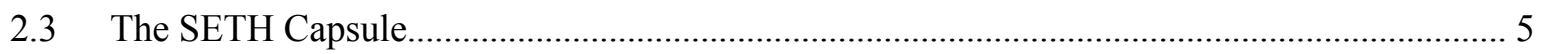

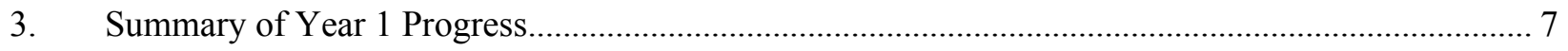

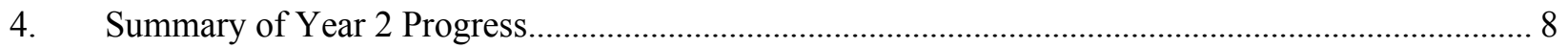

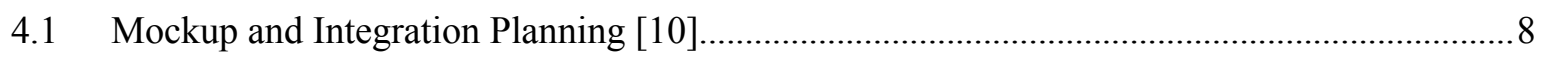

4.2 Initial Prototype Sensor Design and Evaluation [11]....................................................... 9

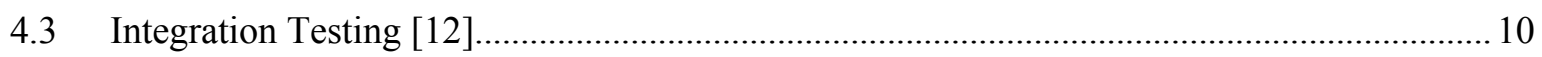

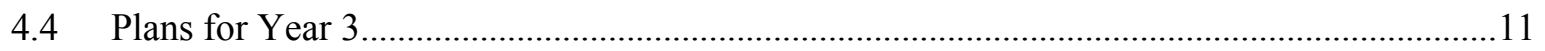

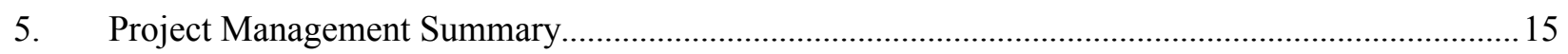

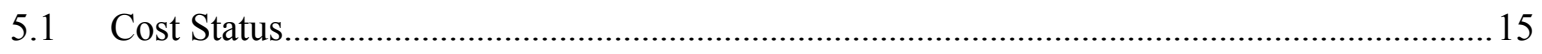

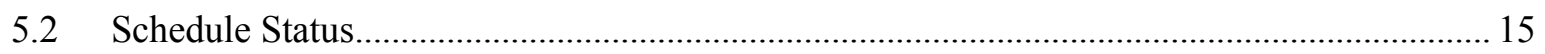

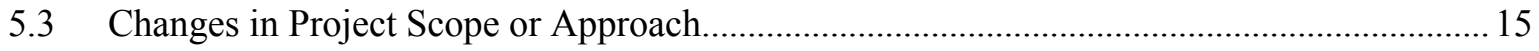

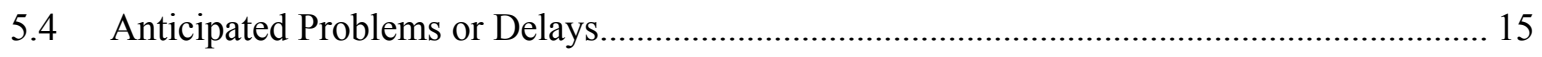

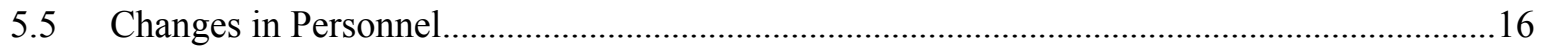

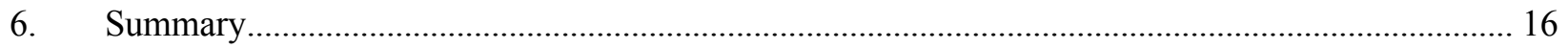

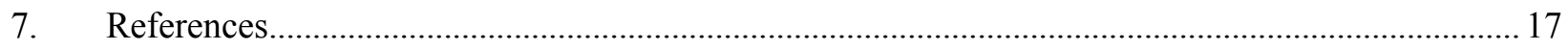




\section{FIGURES}

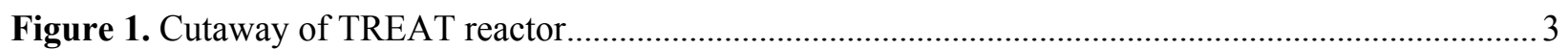

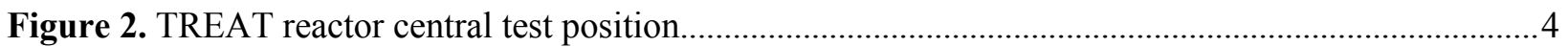

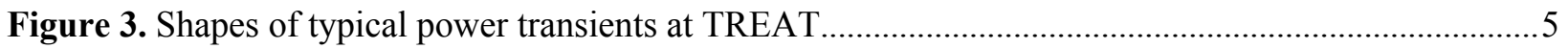

Figure 4. SETH module and integration within BUSTER .................................................................

Figure 5. SETH capsule internal sensor supports and fuel pin surrogate.................................................... 7

Figure 6. Printed titanium SETH capsule and drawing of SETH lid with hanger structure, fuel

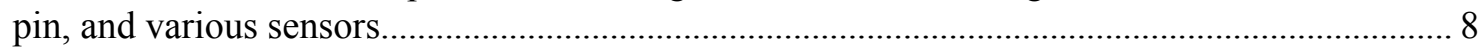

Figure 7. Simplified piezoelectric transducer for concurrent testing........................................................ 9

Figure 8. Dynamic testing setup used to compare UT and DIC results/.................................................. 10

Figure 9. Results of dynamic testing showing agreement between DIC and UT results...........................10

Figure 10. Prototype sensor integrated into SETH hanger structure.........................................................11

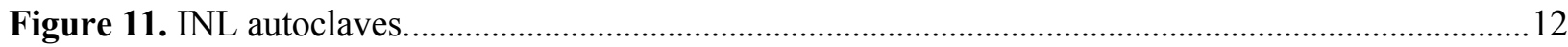

Figure 12. Cartridge heater installed within SETH capsule................................................................... 13

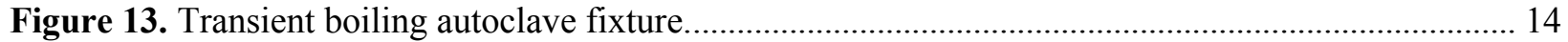

TABLES

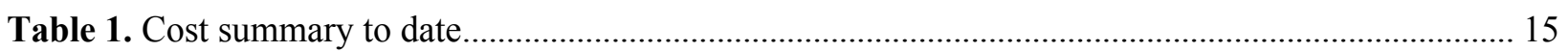

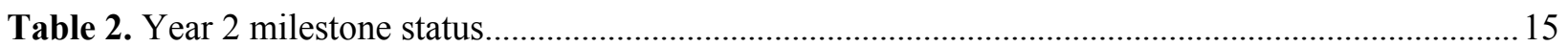




\section{ACRONYMS and ABBREVIATIONS}

AlN

BiT

EMAT

DIC

DOE-NE

LVDT

NDE

NEET-ASI

PZT

PWR

SETH

TREAT

\author{
Aluminum Nitride \\ Bismuth Titanate \\ Electromagnetic Acoustic Transducer \\ Digital Image Correlation \\ Department of Energy-Nuclear Energy \\ Linear Variable Differential Transformer \\ Non-Destructive Examination \\ Nuclear Energy Enabling Technologies-Advanced Sensors and \\ Instrumentation \\ Lead Zirconate Titanate \\ Pressurized Water Reactor \\ Separate Effects Test Holder \\ Transient REActor Test Facility
}




\section{Introduction}

The TREAT facility was specifically designed to conduct transient reactor tests to simulate conditions ranging from mild upsets to severe reactor accidents. Transient irradiation of nuclear fuel samples is performed to identify fuel performance limitations. Of particular interest is testing conducted on preirradiated fuel samples to determine end-of-life performance limits that typically dominate fuel design. A significant challenge in these tests is the deployment of instrumentation for quantifying fuel condition (such as temperature, thermal conductivity, and mechanical condition) while minimizing any changes in these conditions due to the presence of the sensor itself.

A host of instrumentation was used during the operation of TREAT between 1959 and 1994 [1] to generate data necessary for fuel performance quantification. Much of the instrumentation capability from the previous TREAT operations will need to be resurrected, and a significant development, qualification, and integration effort may be necessary before some of these measurement technologies can be redeployed. The unique operating characteristics of TREAT (short bursts of high energy radiation) also challenge many sensors and instrumentation that may otherwise be deployed in-pile in test reactors. Ongoing research and development is addressing several instrumentation needs for TREAT experiments, with details of these advances documented elsewhere [1-3].

Among the key parameters of interest for monitoring during transient tests is the deformation of each component of the fuel pin. While linear variable differential transformer (LVDT) transducers are a potential solution, the sensitivity and response times of these sensors may be limited. The size of typical LVDTs and need for a push-rod connected to the sample make them intrusive and difficult to use in a constrained environment (such as the test capsules proposed for use in TREAT [3]. In addition, typical LVDT sensors are limited in their ability to provide data on radial deformation of the fuel pins.

An ultrasonic measurement approach could enable rapid, accurate measurements of deformation in axial and radial directions in fuel pins during TREAT irradiation tests. This is the focus of the work described in this report.

The overall objective of this work is to design an ultrasonic sensor capable of rapid, non-contact, insitu measurements of dimensional changes in pre-irradiated fuel during re-irradiation. Specifically, the proposed sensor design will target:

- Reliable operation at elevated temperatures (between $\sim 300^{\circ} \mathrm{C}$ and $600^{\circ} \mathrm{C}$ )

- Design compatibility with proposed near-term TREAT irradiation capsule concept designs [3]

- Direct measurement of fuel dimensional changes, including fuel rod diameter

- High-speed measurements to enable rapid characterization of changes during a transient test.

In addressing this research scope, we will leverage prior research in long-term piezoelectric sensor material survivability using in-pile sensor tests in materials test reactors (including previous NEET-ASI research) and in ultrasonic characterization of irradiated fuel specimens [4-7]. While irradiation (specifically, total dose) and time-at-temperature (especially above $\sim 600^{\circ} \mathrm{C}$ ) are not expected to be a significant issue during TREAT transient tests, the ability to design the sensor to withstand such environments will increase sensor and measurement reliability. Prior research in compensation techniques [8], and advances in measurement science including higher bandwidth instrumentation, high-speed data acquisition devices and low noise electronics enable increased accuracy and precision from ultrasonic measurements. Recent results from post-irradiation examination of irradiated fuel using commercial-offthe-shelf ultrasonic probes and instrumentation [9] also demonstrated the potential sensitivity of ultrasonic measurements to fuel dimensions (and potentially to microstructure) and the ease with which commercial ultrasonic probes and instrumentation can be applied to irradiated fuel. 


\subsection{Objectives}

The overall objective of this work is to design an ultrasonic sensor capable of rapid in situ measurements of dimensional changes in pre-irradiated fuel during transient irradiation experiments.

This report is a summary of the information described in greater detail in previously submitted milestone technical reports (10-12) that described the planning for mock-up testing facilities and integration of the sensor with the Separate Effects Test Holder (SETH) capsule, the status of development testing of a prototype sensor, and the status of mock-up and integration testing.

\subsection{Report Organization}

Section 2 of this report briefly discusses background information on ultrasonic measurements. Section 3 briefly summarizes progress made in Year 1. Section 4 details progress made in Year 2. Section 5 summarizes project management status. The report is summarized in Section 6.

\section{Background}

Ultrasonic measurements of deformation can provide nondestructive measurements of dimensional changes rapidly (within tens to hundreds of microseconds). Further these methods are sensitive to both microstructural changes due to damage (from thermal, mechanical, and irradiation environments) and gross structural changes (such as swelling). As a result, ultrasonic methods have been applied to address needs in the nondestructive evaluation of structural components in nuclear power plants (including fuel cladding) during periodic pre-service and in-service inspections.

Ultrasonic measurements have been successfully used for nondestructive materials characterization, including nondestructive evaluation (NDE) of degradation and damage [13], microstructure characterization [14], quantification and visualization of structural changes [15, 16] and process control [17]. Ultrasonic NDE is a critical element of the nuclear power industry's in-service inspection program for maintaining the integrity of the pressure boundary [18], and is being actively investigated for postirradiation examination of fuels [19]. Ultrasonic measurements, typically performed at $10 \mathrm{MHz}$ or higher [4], performed post irradiation show that fuel microstructural parameters, such as porosity and grain size, can be correlated to ultrasonic velocity $[5,19]$.

Ultrasonic methods historically have seen limited applicability to environments with high temperatures and irradiation. Though some environmental factors (such as temperature) affect the measurement (sound speed, for instance), the limitation is primarily due to the probes themselves. Most commonly, lead-zirconate-titanate (PZT) is used as the piezoelectric sensor material for ultrasonic nondestructive measurements. PZT is limited in its applicability at elevated temperatures (approximately above $300^{\circ} \mathrm{C}$ ). However, recent tests (through DOE-NE's NEET-ASI program) have identified a number of alternatives that can operate at elevated temperatures (in excess of $400^{\circ} \mathrm{C}$ ) and can survive irradiation [6]. Certain grades of PZT have also been demonstrated for use in imaging under-sodium in sodium fast reactors [15]. A number of prior studies have also examined piezoelectric sensor material survivability using in-pile sensor tests in materials test reactors and in ultrasonic characterization of irradiated fuel specimens $[4,5,8,19]$. Recent advances in high-temperature ultrasonic sensor design has led to ultrasonic sensors that have demonstrated survivability at $550^{\circ} \mathrm{C}$ for several weeks, under thermal cycling [20].

\subsection{TREAT}

TREAT (cutaway view shown in Figure 1) was constructed in the late 1950's and, after extensive use, was placed in standby in 1994 [21]. TREAT was designed to evaluate reactor fuels and structural materials under conditions simulating various types of nuclear excursions and transient undercooling situations in a nuclear reactor. Fuel meltdowns, reactions between coolant and metals (structural, fuel, or 
cladding), interaction between overheated fuel and coolant, and the transient behavior of fuels for high temperature systems can be studied. TREAT is an air-cooled reactor driven by a core of graphite blocks having a small concentration of dispersed uranium oxide. Prismatic columns of these graphite-fuel blocks are hermetically encapsulated in zirconium alloy sheet metal cladding. Aluminum-sheathed graphite reflector blocks at top and bottom of each fuel column form a fuel assembly with $1.2 \mathrm{~m}$ of active core length. Along with control rod, experiment, and graphite reflector assemblies, these fuel assemblies are placed on a $19 \times 19$ gridplate with 361 available positions; creating a configurable core that can be adjusted to suit particular nuclear parameters or experimental objectives [22].

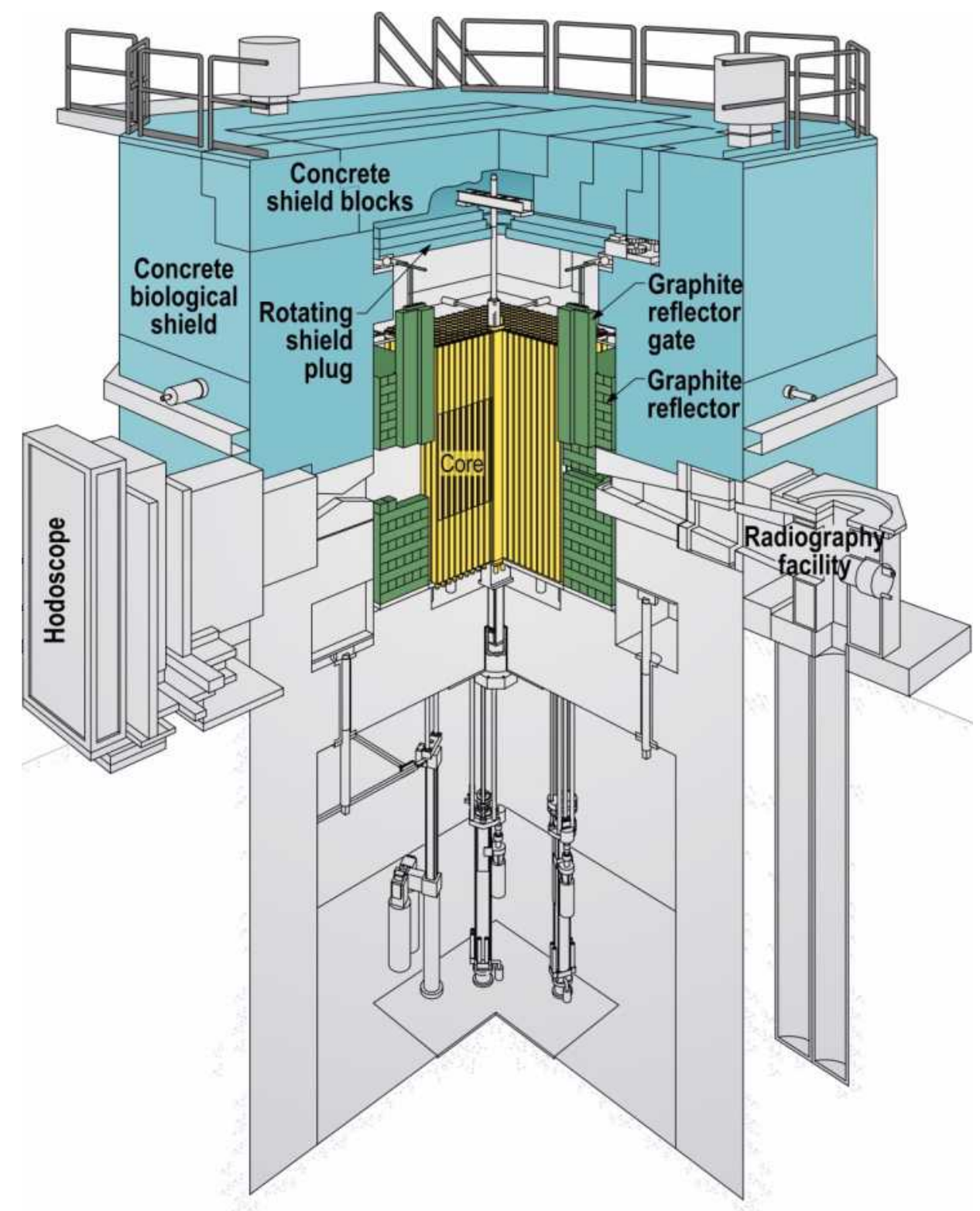

Figure 1. Cutaway of TREAT reactor.

A few fuel assemblies are typically removed from the central core positions to create a cavity for 
experiments (as shown in Figure 2). Experiment assemblies are typically removed from or placed into the core through a slot in the reactor's upper rotating shield plug, handled outside the reactor using shielded casks, and stowed below grade in storage holes when not in use. Four slots can be opened through the vertical concrete shield walls and permanent graphite reflector surrounding the above-grade core to provide various capabilities [23]. TREAT experiment rigs are, in essence, self-contained reactor vessels in which the neutrons are produced externally. Each rig (static capsule or loop) has its own double containment boundary and is simply lowered into the reactor test position, allowing for high throughput of experiments.

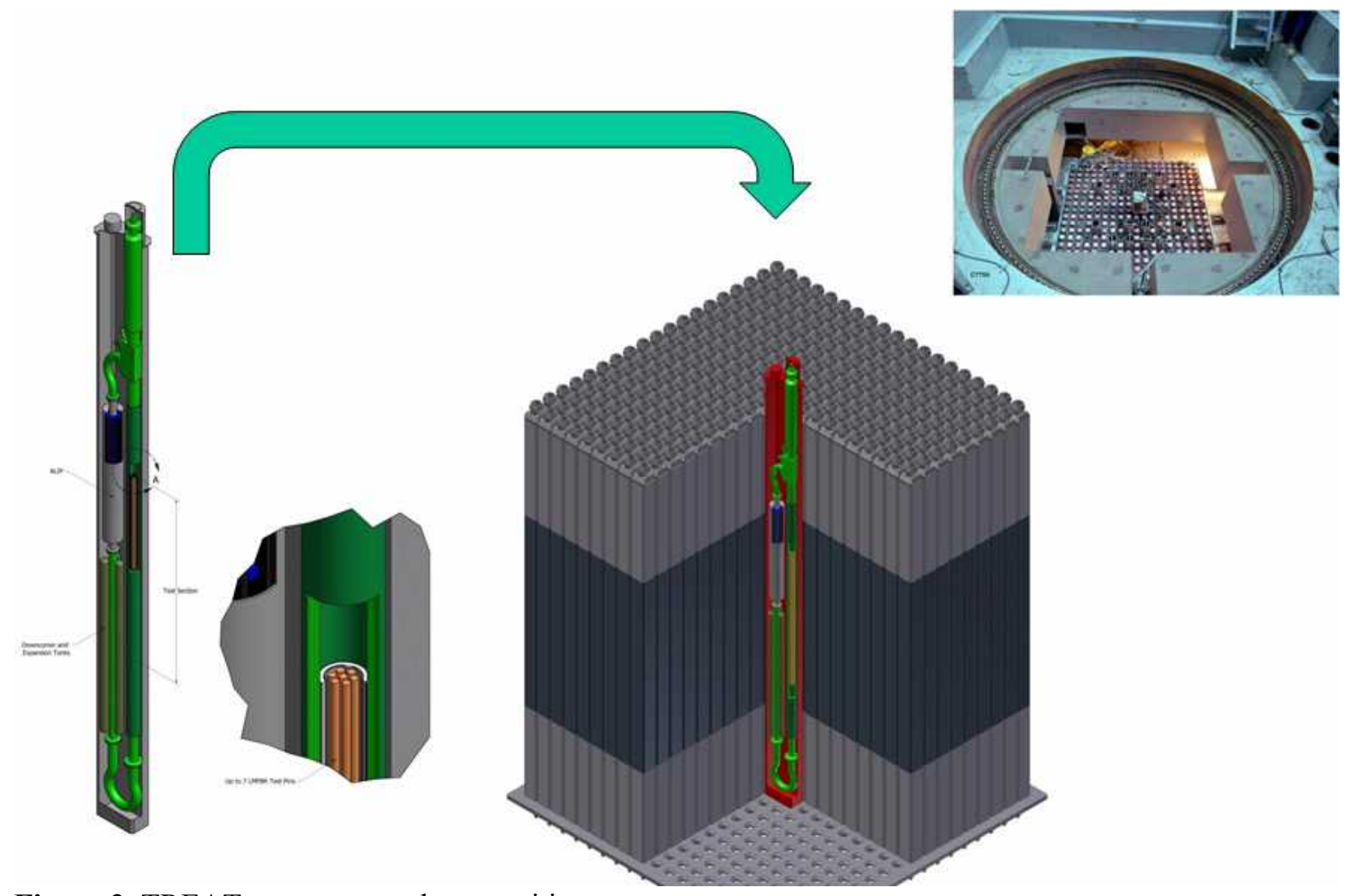

Figure 2. TREAT reactor central test position.

\subsection{Transients}

TREAT's transients can be shaped to vary over several orders of magnitude in terms of both reactor power and transient duration; the precise shape being practically governed simply by the core energy capacity (currently $2500 \mathrm{MJ}$ ). The shape of the TREAT is arbitrary, as long as the power/time profile is a function and the total integral energy is less than 2500 MJ. Figure 3 shows several simple transients which may be considered to encompass the extremes of TREAT transients in terms of power and duration [23]. 


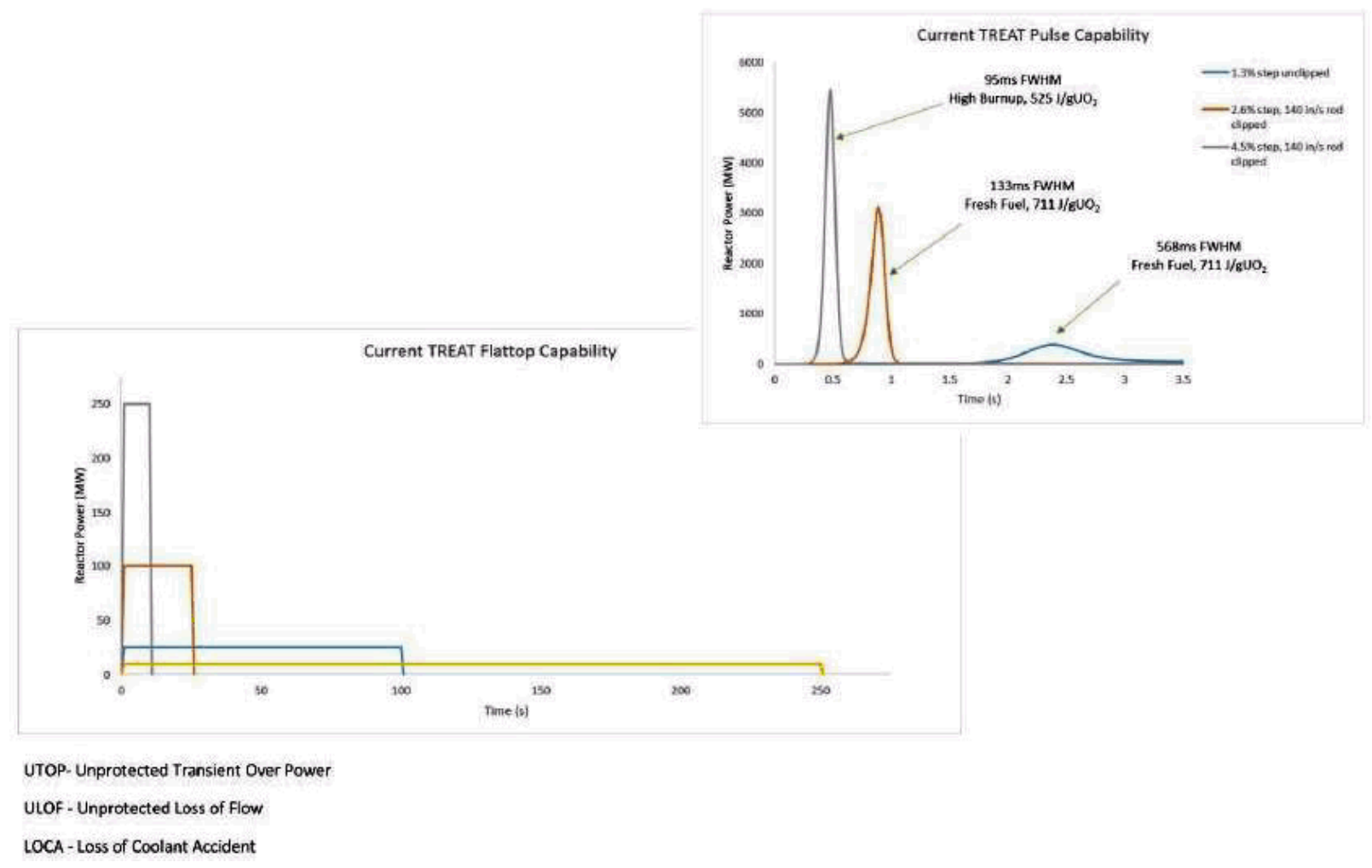

Figure 3. Shapes of typical power transients at TREAT.

\subsection{The SETH Capsule}

The Separate Effects Test Holder (SETH), shown in Figure 4 [23-25], contains sufficient volume for testing several forms of fuel samples, including LWR rodlets, MTR style plate fuels, etc., in nonprototypic sizes. The space available can also accommodate significant instrumentation, with feedthroughs using standard compression seals which can accommodate multiple 1-2 mm diameter MIMS cables. The SETH module does not currently include the capability for prototypic reactor coolant conditions (e.g. hot pressurized water, liquid sodium, etc.), but a room temperature, atmospheric pressure, water environment is planned. SETH has been identified as an ideal testbed for many applications including:

- Screening survivability tests. First round of testing for sensor in TREAT.

- Testing of sensor for sensitivity to reactor effects and signal noise characterization.

- Qualification testing with surrogate samples to demonstrate sensor performance.

Figure 5 shows a more detailed view of the SETH lid illustrating one planned test configuration. Aluminum structures are used for holding the central test specimen (a fuel rodlet or surrogate) as well as the instrumentation. These holders may be specially designed for different configurations and specimens, giving the SETH module tremendous flexibility for testing sensors in a variety of configurations. 


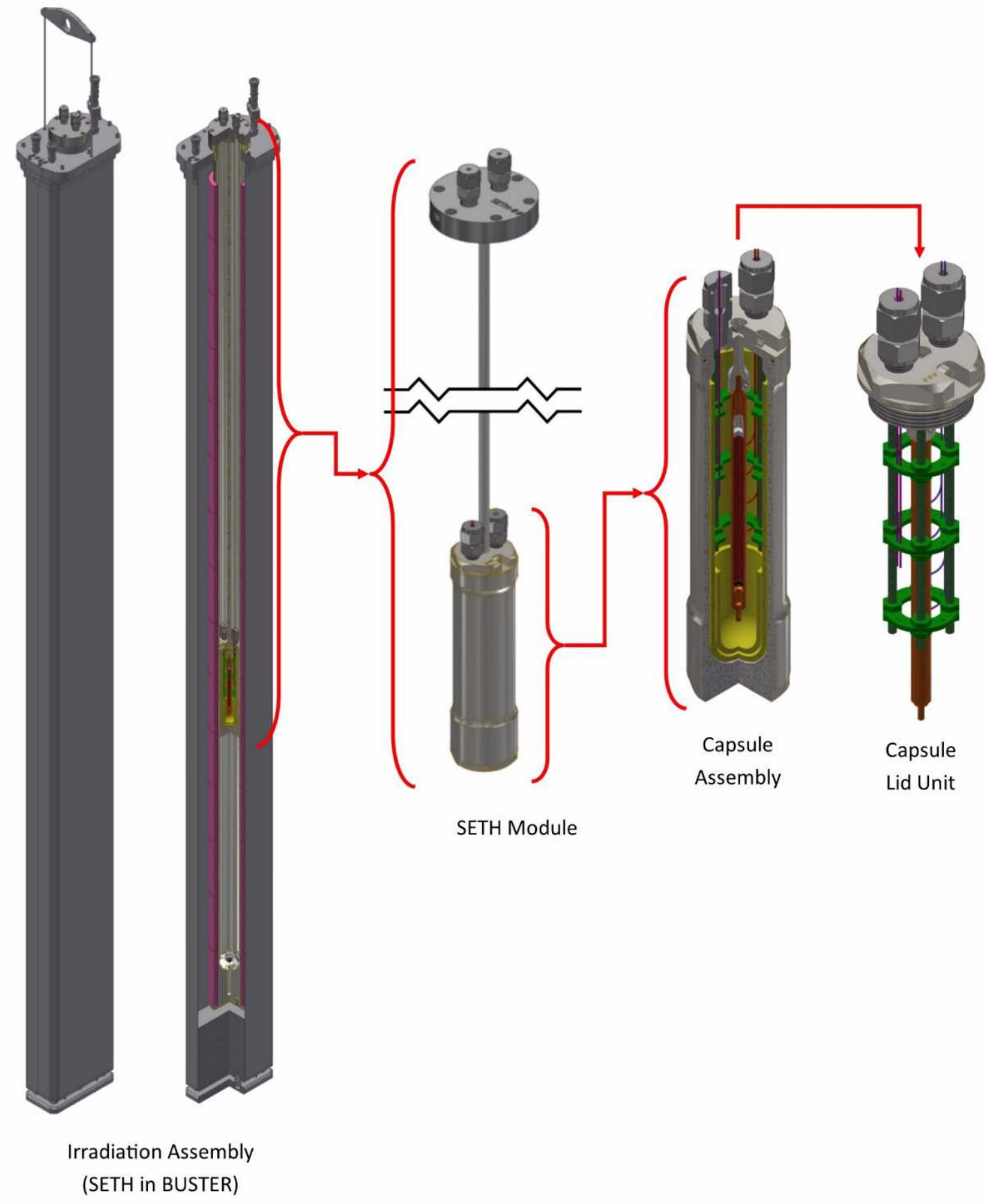

Figure 4. SETH module and integration within BUSTER. 


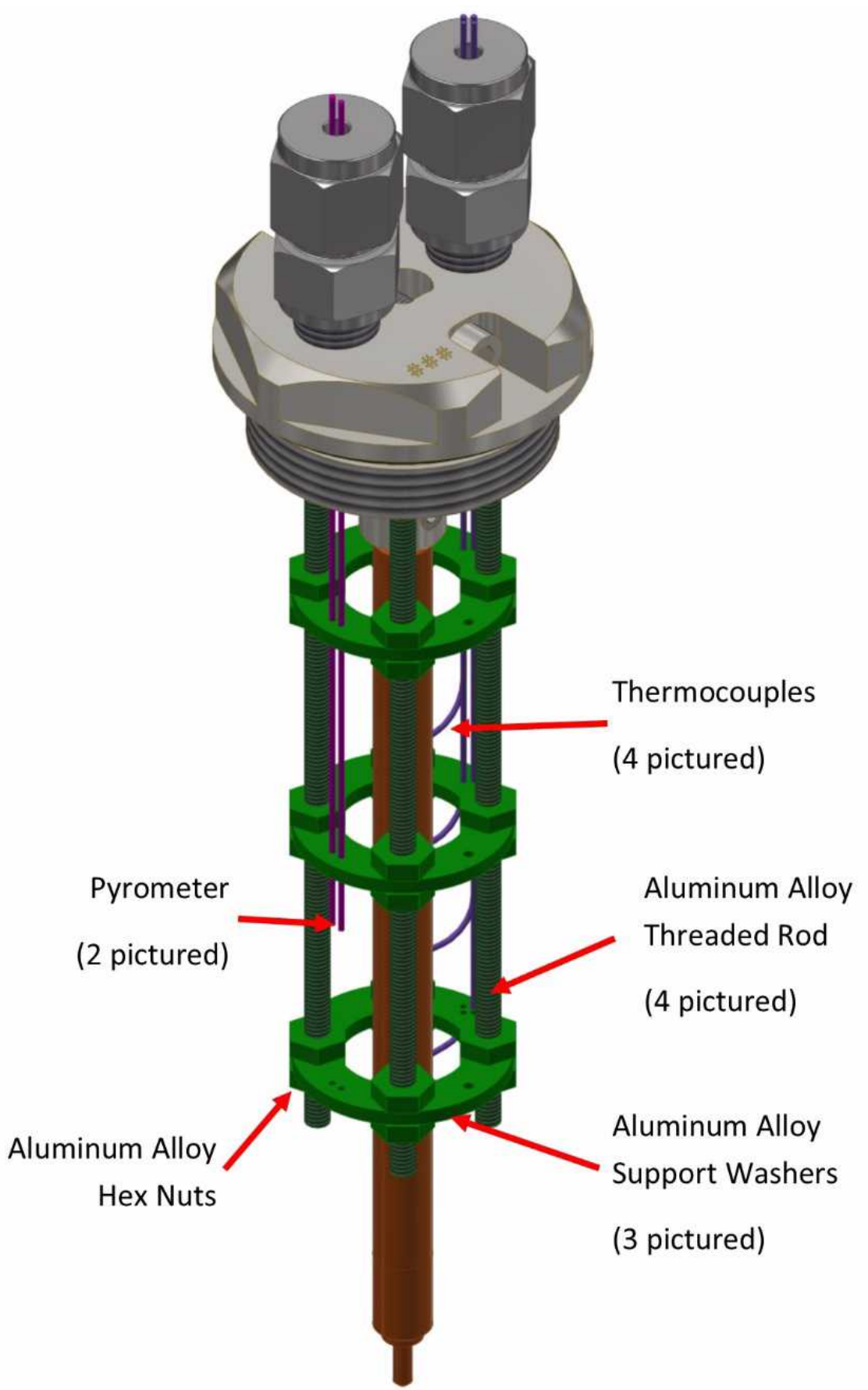

Figure 5. SETH capsule internal sensor supports and fuel pin surrogate.

\section{Summary of Year 1 Progress}

A sensor requirements report [26] was developed to document relevant information detailing the TREAT reactor, likely experiment capsules, and facilities. Also, information on the required measurement speed and resolution and design constraints were documented through literature reviews and interactions with TREAT team leads. The SETH capsule was selected as a first target application, as it is planned for near term deployment, matches most of the design considerations of other planned capsules, and is designed to be used for sensor testing, along with fuel and material irradiations. 
Piezoelectric and magnetostrictive materials were considered for use in the deformation sensor [27]. Materials of high interest included aluminum nitride, bismuth titanate, lithium tetraborate, lithium niobate, Remendur, and Galfenol. Other sensor types, such as electromagnetic acoustic transducer (EMAT) sensors were also assessed. Piezoelectric sensors, with bismuth titanate and lithium niobate being used as the active elements, are considered the most promising with some focus also devoted to fabrication of aluminum nitride (AIN) sensors.

The sensor conceptual design [28] was based on previous work designing sensors for temperatures exceeding $550^{\circ} \mathrm{C}$. Due to material survivability at these elevated temperatures, conventional bonding techniques are not applicable and a pressure-coupled approach is used, being careful of thermal expansion effects of the differing materials. This sensor design was used as a starting point for the design of a sensor to fit within the constraints of the SETH.

\section{Summary of Year 2 Progress}

\subsection{Mockup and Integration Planning [10]}

This report described progress on planning for integration of the sensor into TREAT experiments and on development of mock-up testing capabilities. This included descriptions of printed SETH capsules, both plastic and metallic, and identification of testing facilities to be used for prototypic ex-core testing.

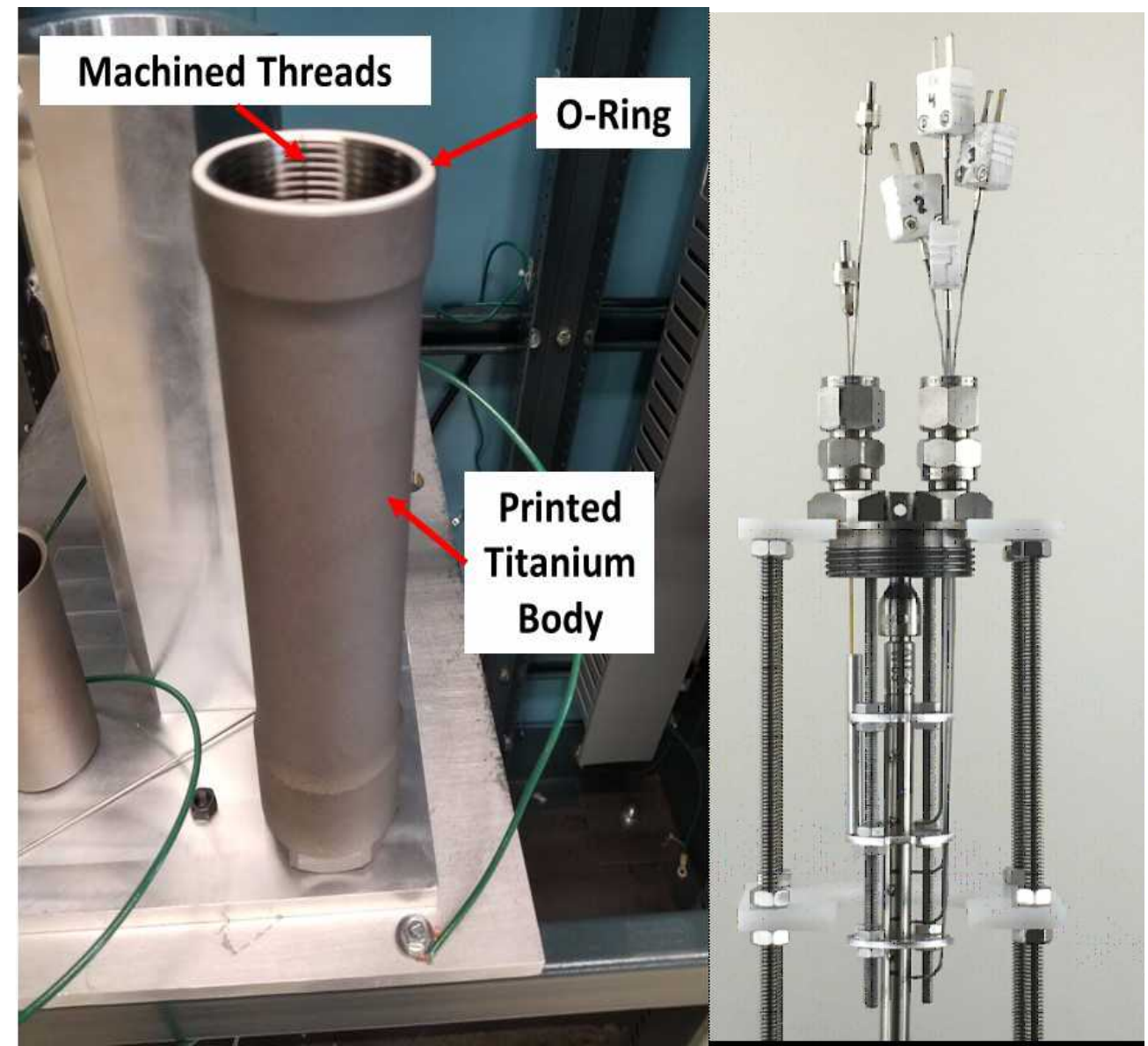

Figure 6. Printed titanium SETH capsule and drawing of SETH lid with hanger structure, fuel pin, and various sensors.

Also detailed were plans for concurrent testing of a simplified transducer (Figure 7) within the 
TREAT reactor, which will be used to assess the piezoelectric materials under consideration and to develop a data acquisition strategy for future testing.

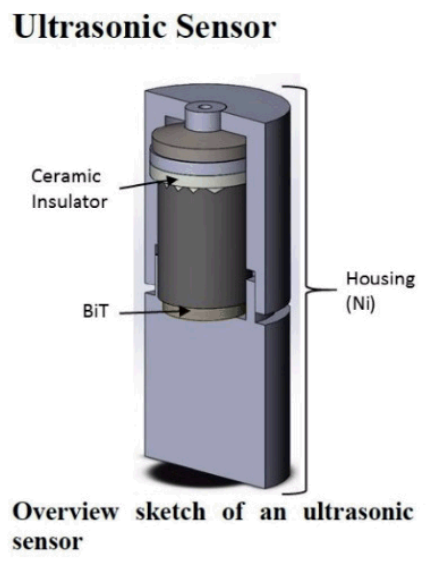

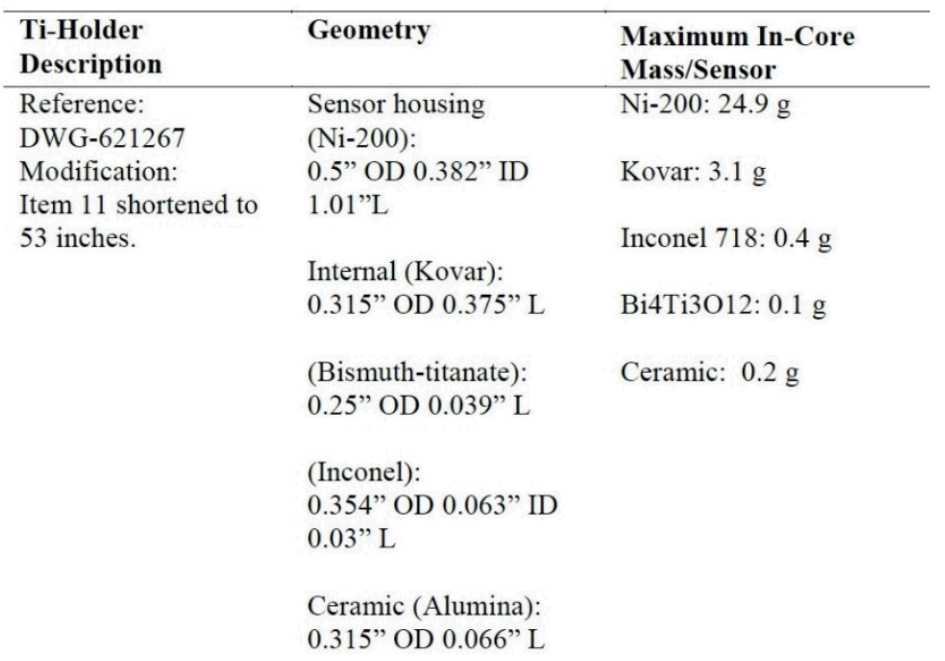

Figure 7. Simplified piezoelectric transducer for concurrent testing.

\subsection{Initial Prototype Sensor Design and Evaluation [11]}

This report described a potential prototype sensor design involving one or more pairs of transducer elements positioned $180^{\circ}$ from one another with the tube being measured located between them. This design was shown in both static and dynamic tests to be sensitive to changes in tube diameter during expansion due to outward stresses and potentially to tube wall thickness at desired levels of accuracy. The tests described in this report demonstrated that the tube diameter values recorded by the measurements of the ultrasonic sensor design match measurements of digital image correlation (DIC) and calipers well, as shown in Figures 8 and 9.

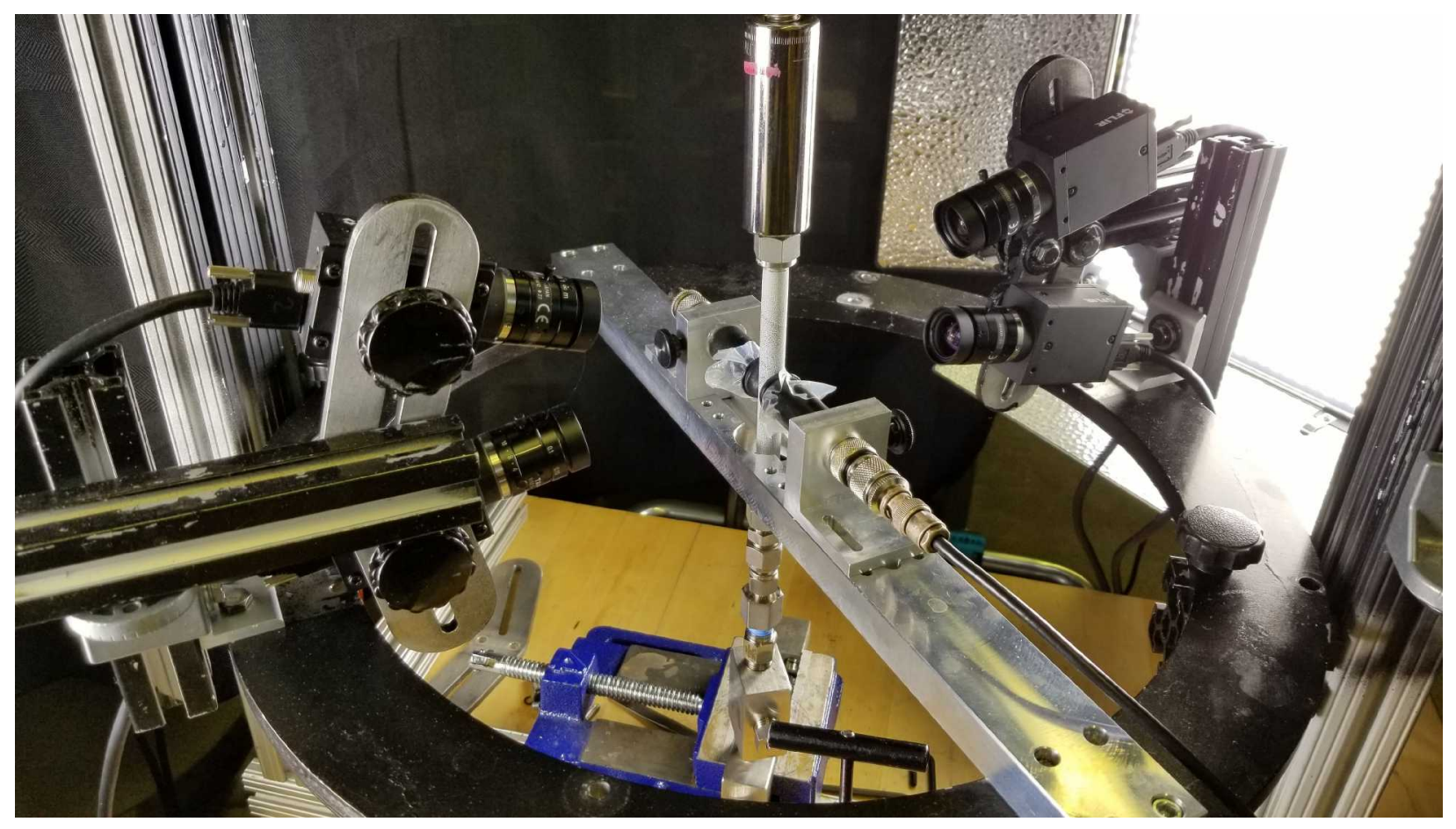


Figure 8. Dynamic testing setup used to compare UT and DIC results

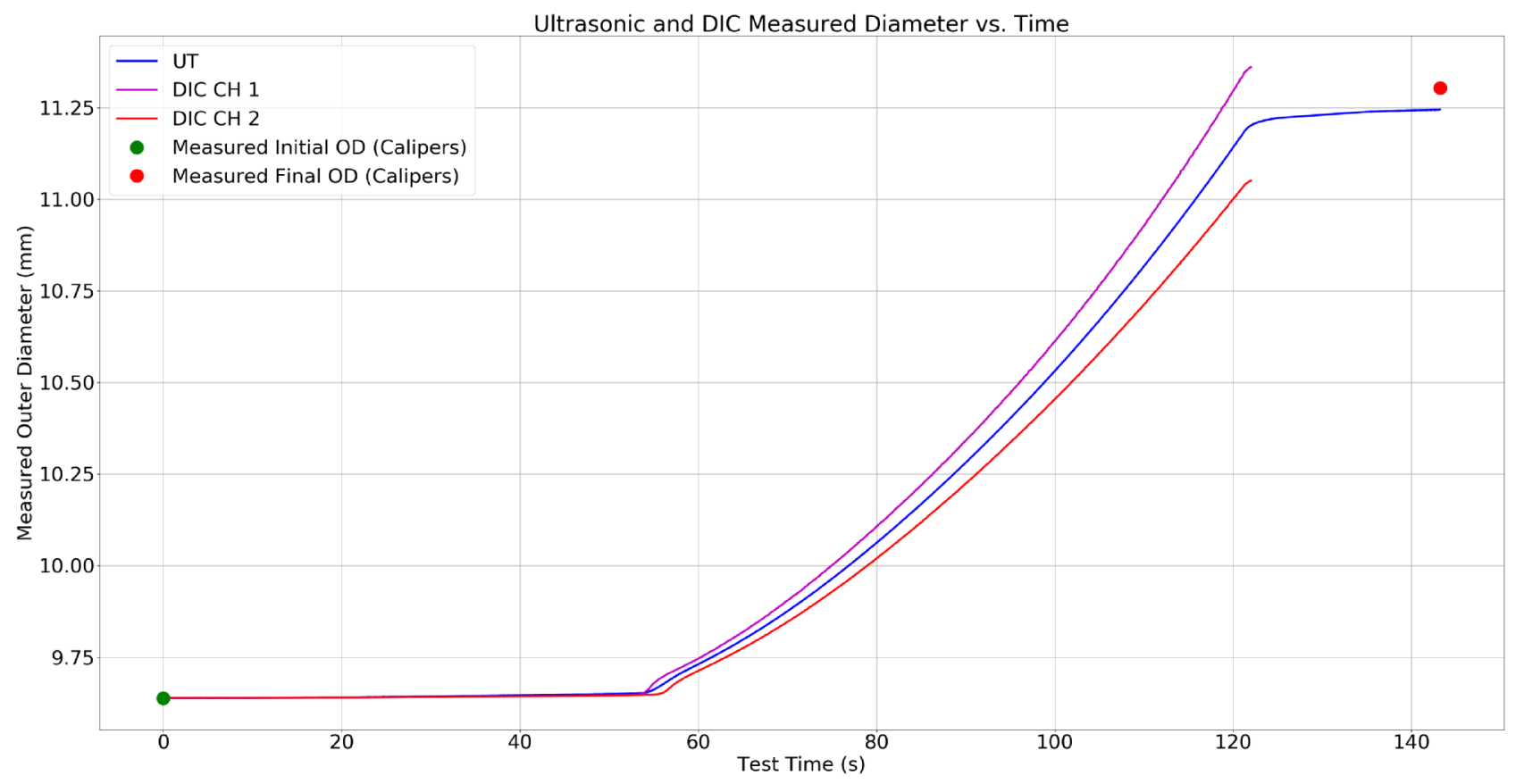

Figure 9. Results of dynamic testing showing agreement between DIC and UT results.

\subsection{Integration Testing [12]}

This report documented efforts to refine, fabricate, and test the sensor design presented previously with the requirement that it fit within the confines of a SETH capsule. This design utilizes materials that will survive at higher temperatures. Functionality requirements led to the desire to develop brazed or pressure-coupled designs to eliminate the use of coupling materials that may not function well at higher temperatures. Brazing attempts with AIN failed due to deflection of the nickel cup during brazing. Future attempts will use a thicker cup that will be mechanically thinned after brazing to prevent this phenomenon. Pressure coupling attempts with BiT were also unsuccessful as it was determined that much more pressure was necessary than anticipated to generate signals of desired quality. In order to address this result, future designs will use a high temperature conductive coupling material in place of a pressure coupling design. This coupling of a BiT element to backing material with a high temperature, electrically conductive coupling material is currently being pursued. 

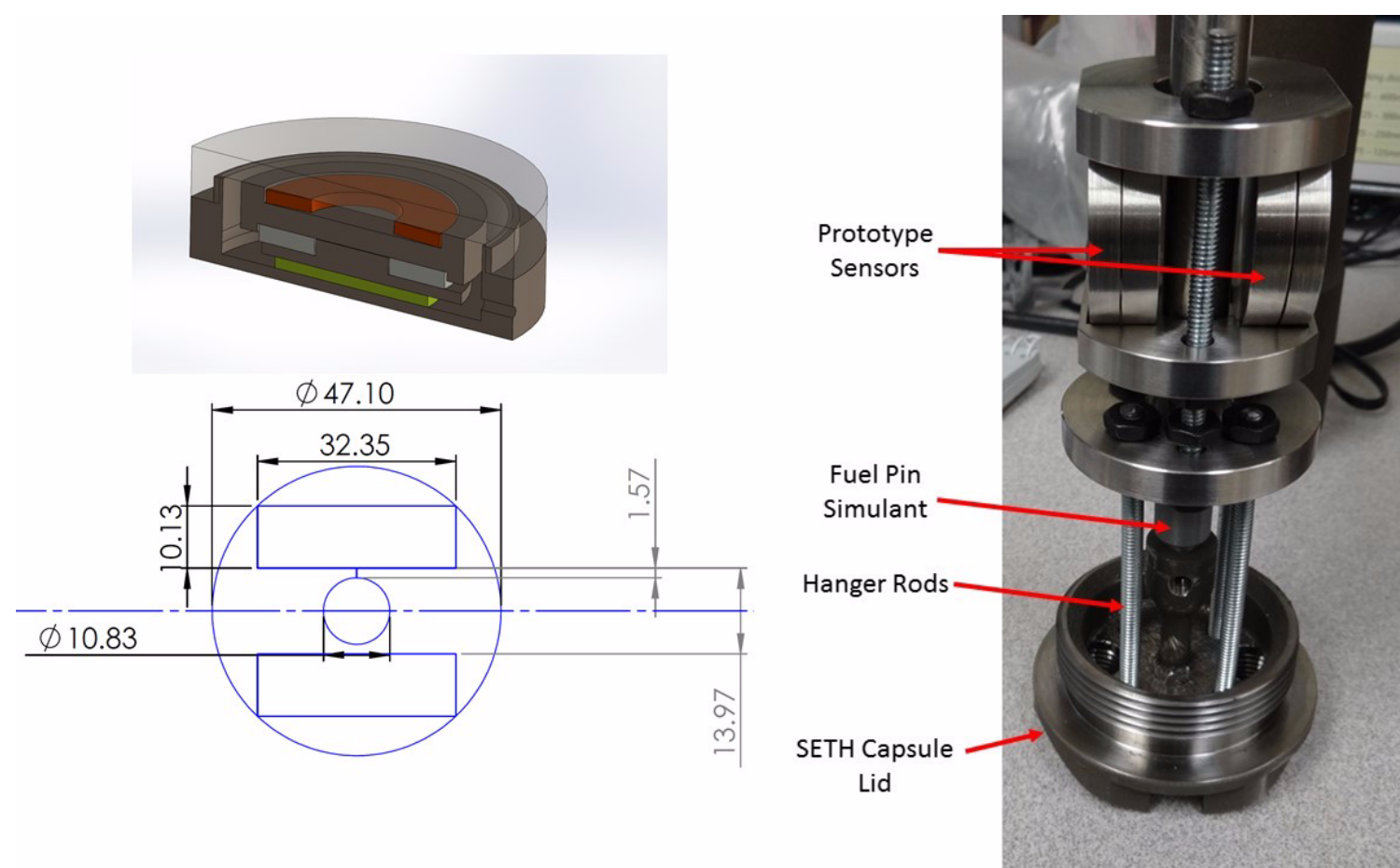

Figure 10. Prototype sensor integrated into SETH hanger structure.

\subsection{Plans for Year 3}

As just mentioned, the first objective of the third year of this project is to use the lessons learned in the second year to produce a functional sensor from the appropriate combination of piezoelectric element, backing material, and bonding technique. Subsequently, static and dynamic tests will be executed in order to document the sensor performance.

The next stage of testing will be in semi-prototypic environments, which will include laboratory testing in autoclaves and TREAT testing of a simplified piezoelectric transducer as part of ongoing TREAT concurrent sensor testing.

Several options are being considered for in-lab testing. The first option is autoclave testing. Autoclaves at INL were designed to mimic steady-state PWR temperature and pressure, with maximum levels of $2500 \mathrm{PSI}$ and $325^{\circ} \mathrm{C}$. The autoclaves have inner diameter of $127 \mathrm{~mm}$ and sufficient length to accommodate either a free hanging sensor and fuel rod simulant or a SETH capsule containing the sensor and fuel simulant. 


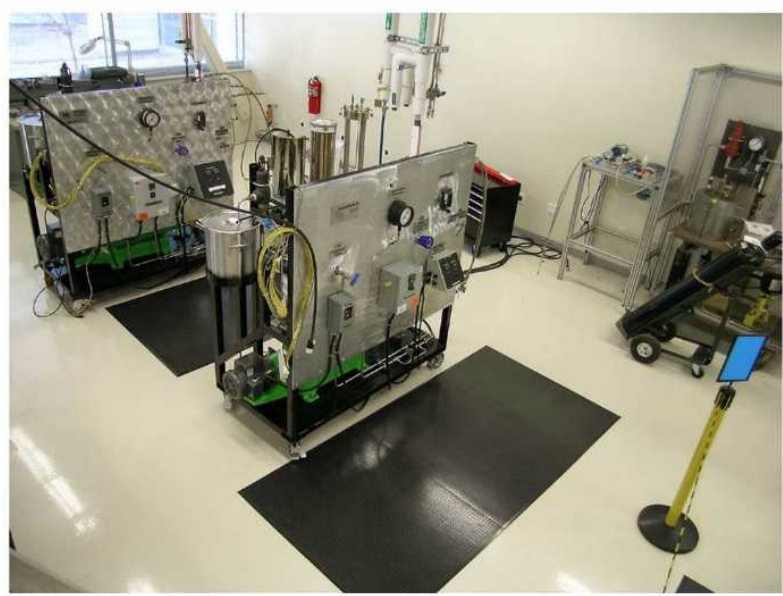

Autoclave Area



Top View

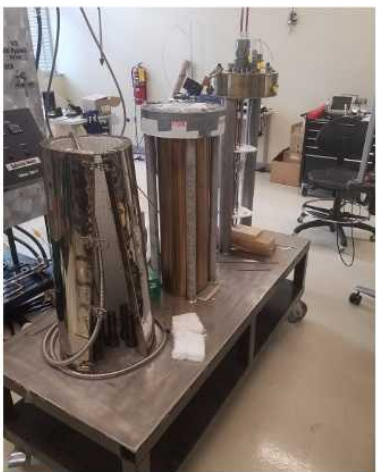

Autoclave 3

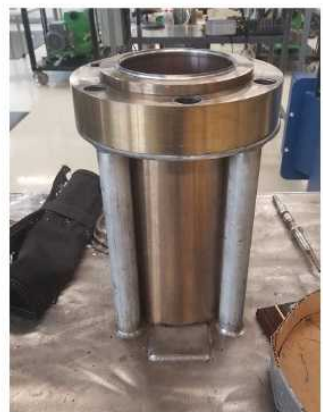

Autoclave 2

Figure 11. INL autoclaves.

The second option is a water filled SETH capsule heated with a cartridge heater. Previously, this setup (shown in Figure 12) was used with a gas fill to reach $800{ }^{\circ} \mathrm{C}$ for testing temperature sensors. Some modifications will be necessary to operate the cartridge heater under water filled conditions and, without the ability to operate under pressure, temperatures would be limited to natural boiling temperature at local atmospheric pressure. 


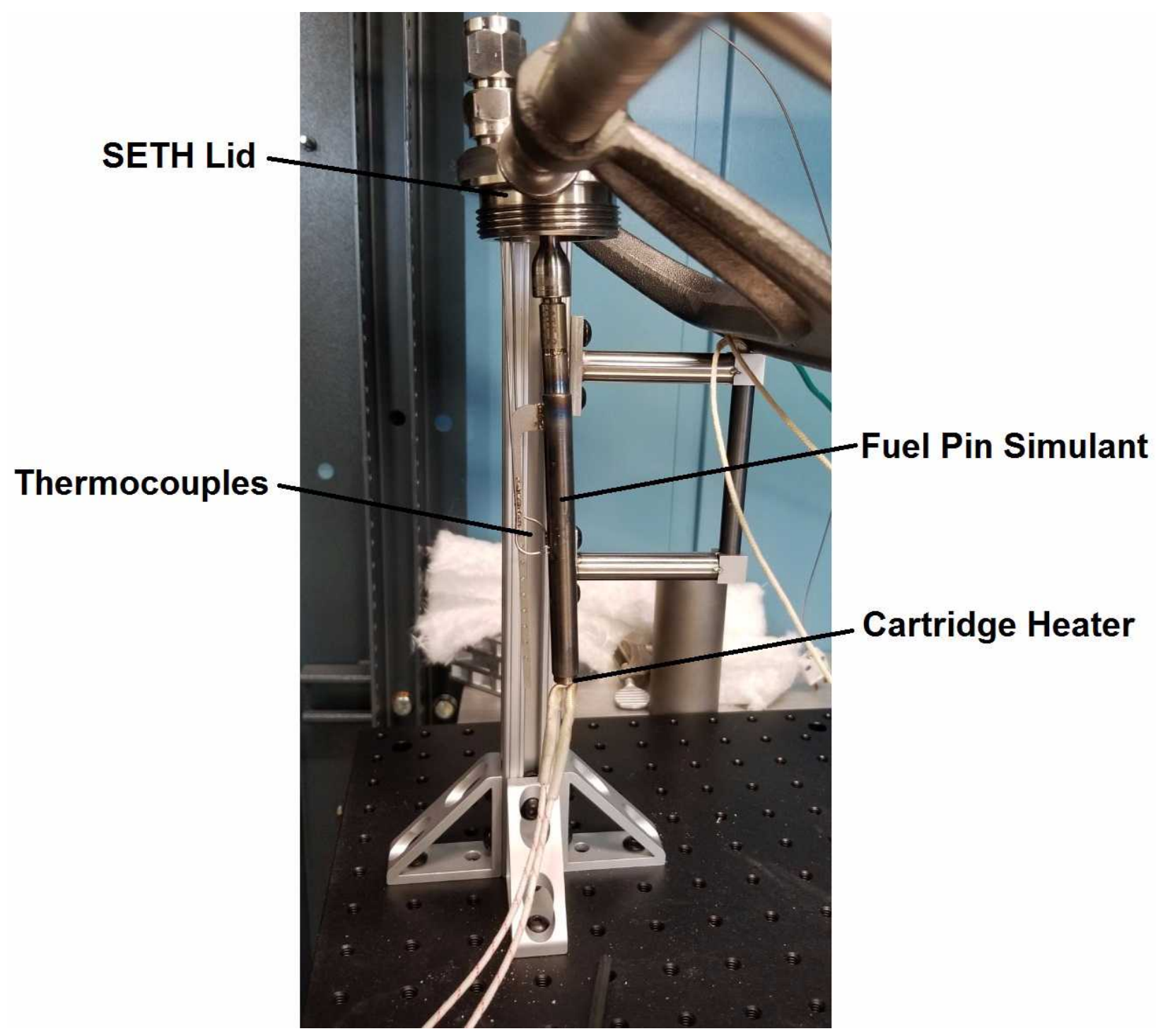

Figure 12. Cartridge heater installed within SETH capsule.

Last is a test fixture under development for mimicking the rapid boiling which occurs under TREAT transients. This test fixture utilizes a capacitor bank to rapidly heat a test section, within an autoclave, through Joule heating, approximating the heat rates provided by TREAT transient irradiations. This capability is still developmental and, as of this report, has not been tested. If successful, this would be an ideal facility for testing the ultrasonic deformation sensor. 


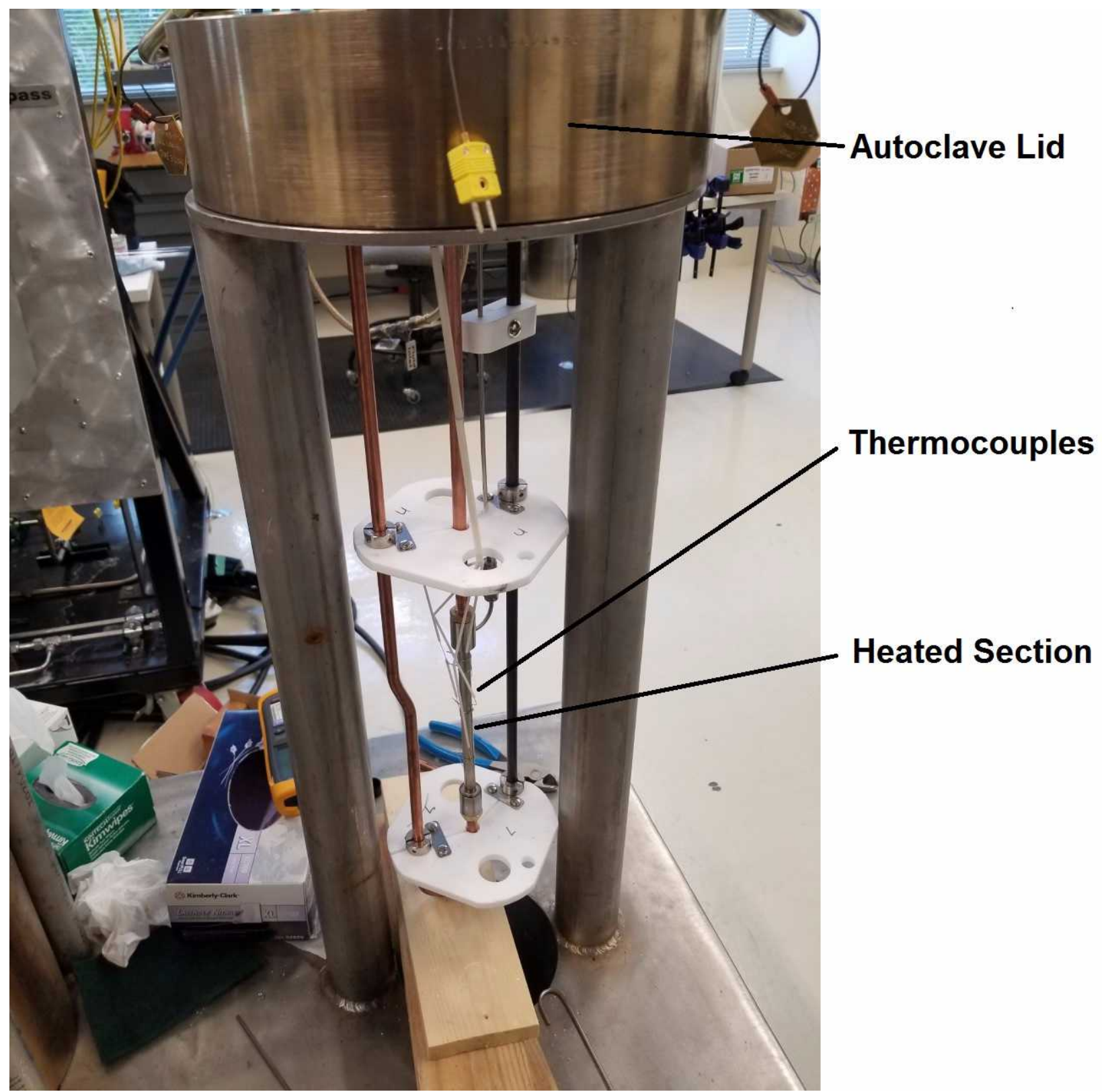

Figure 13. Transient boiling autoclave fixture.

Testing of a simplified transducer design in TREAT was planned for May of 2019 (as described in Section 4.1) but was delayed due to delays in receiving machined parts for the transducer. Currently, the parts have been received and assembly of the transducer, using a Bit element, is underway. The test is planned for November 2020.

Other third year activities will include optimization of the sensor design based on integration and mock-up testing results, development of measurement algorithms, and development of an irradiation test plan for qualification of the sensor. 


\section{Project Management Summary}

\subsection{Cost Status}

Table 1 summarizes the costs in Year 1 and Year 2 of the project.

Table 1. Cost summary to date

\begin{tabular}{lll}
\hline & Yearly Budget & Actual Yearly Costs \\
\hline Budget Year 1 & $\$ 279,000$ & $\$ 167,120$ \\
Budget Year 2 + Year 1 Carryover & $\$ 354,000+\$ 111,880$ & $\$ 482,636$ \\
Budget Year 3 & $\$ 367,000-\$ 16,756=\$ 350,244$ & \\
Total & $\$ 1,000,000$ & \\
\hline
\end{tabular}

\subsection{Schedule Status}

Table 2 summarizes the status of the milestones and deliverables for Year 1 of this project.

Table 2. Year 2 milestone status

\begin{tabular}{clcc}
\hline \multicolumn{1}{c}{ Milestone Number } & \multicolumn{1}{c}{ Title } & Due Date & Submission Date \\
\hline M3CA-17-WA-PN-1002-018 & $\begin{array}{l}\text { Complete TREAT test capsule } \\
\text { mockup and initial sensor } \\
\text { integration planning }\end{array}$ & $3 / 27 / 2019$ & $3 / 27 / 2019$ \\
M2CA-17-WA-PN-1002-019 & $\begin{array}{l}\text { Complete initial ultrasonic } \\
\text { sensor prototype design and } \\
\text { preliminary evaluation }\end{array}$ & $6 / 5 / 2019$ & $6 / 5 / 2019$ \\
M3CA-17-WA-PN-1002-0119 & $\begin{array}{l}\text { Complete initial integration } \\
\text { testing of prototypic ultrasonic } \\
\text { sensor design }\end{array}$ & $9 / 30 / 2019$ & $9 / 27 / 2019$ \\
\hline
\end{tabular}

\subsection{Changes in Project Scope or Approach}

Opportunities to test sensors in TREAT coolant channels during transient experiments, called concurrent tests, were not expected during the proposal phase of this project. These tests have provided a relatively cheap and fast way of testing transducers fundamentally similar to the envisioned sensor; but simplified in design. Given this opportunity, at least one concurrent test will be completed. It is expected that this test will provide insight into transducer performance under transient conditions and accelerate integration of test electronics with TREAT facility infrastructure.

\subsection{Anticipated Problems or Delays}

Staff availability and procurement difficulties for materials and test specimens delayed activities in Year 1. It was anticipated that in Year 2 new hiring and arrival of equipment would accelerate progress, 
but that has not been the case. Unanticipated difficulties in manufacturing components and lack of access to personnel due to conflicting projects has caused additional delays.

\subsection{Changes in Personnel}

Dr. Ramuhalli transitioned from Pacific Northwest National Laboratory to Oak Ridge National Laboratory but has remained associated with the project.

\section{Summary}

The overall objective of this work is to design an ultrasonic sensor capable of rapid in-situ measurements of fuel rodlet dimensional changes during TREAT transient irradiation testing. This report summarizes the activities and research findings through the end of Year 2 of this three-year project.

Plans for testing of the prototype sensor were developed, with facilities identified for elevated temperature and aqueous environments identified. A prototype sensor design was developed, and initial testing showed good agreement with measurements made with digital image correlation and with calipers. Some difficulties were encountered during the fabrication of the sensor for testing in prototypic environments, but workarounds have been identified. As such, most integration and mock-up testing has been delayed to Year 3.

Year 3 activities will be focused on completion of delayed Year 2 activities, development of an irradiation test plan for qualification of the sensor, optimization of the sensor design based on results of testing, and development of measurement algorithms. 


\section{References}

1. C. Jensen, et. al., "FY17 Report for Instrumentation Development for the Transient Testing Program,” INL/EXT-17-43444, Sept., 2017.

2. Colby Jensen, "Experiment Instrumentation for Transient Testing," Advanced Sensors and Instrumentation 2016 NE I\&C Review, Oct. 12-13, 2016

3. C. Jensen, "Transient testing instrumentation needs," Presented at the 2016 DOE-NE ASI Program Review, October 2016.

4. D. Fourmentel, J. F. Villard, et al, "Acoustic sensor for in-pile fuel rod fission gas release measurement," in First Int'1. Conf. on ANIMMA, 2009, pp. 1-5.

5. K. K. Phani, D. Sanyal, and A. K. Sengupta, "Estimation of elastic properties of nuclear fuel material using longitudinal ultrasonic velocity - A new approach," J. Nucl. Mater., vol. 366, pp. $129-136,6 / 30 / 2007$.

6. J. Daw, J. Rempe, et al., NEET In-Pile Ultrasonic Sensor Enablement-Final Report, Technical Report, PNNL-23746 (INL/EXT-14-32505), 2014.

7. P. N. Bilgunde and L.J. Bond, "Effect of Thermal Degradation on High Temperature Ultrasonic Transducer Performance in Small Modular Reactors," Physics Procedia 70:433-436, 2015.

8. R. Jacobs, P. Ramuhalli, and A. Casella, "Characterization of microstructural differences in irradiated nuclear fuel using ultrasonic NDE," IEEE Trans. UFFC (In preparation).

9. Ramuhalli P, R Jacob, P MacFarlan and A Casella. 2017. "Microstructural Characterization of Irradiated U0.17ZrH1.6 Using Ultrasonic Techniques." Trans. ANS 116(361-364).

10. J. Daw, A. Crawford, R. Skifton, L. Hone, A.M. Casella, M. Prowant, M. Good, C. Hutchinson, T. Roosendaal, R. Montgomery, "Status of Mockup and Integration for Ultrasonic Deformation Sensor for TREAT Experiments," INL/EXT-19-53110, 2019.

11. A.M. Casella, M.S. Good, T. Roosendaal, C. Hutchinson, R. Seffens, M. Prowant, R.O. Montgomery, F. Luzi, P. Ramuhalli, J. Daw, "Complete Initial Ultrasonic Sensor Prototype Design and Preliminary Evaluation," PNNL-28753, 2019.

12. J. Daw, A. Crawford, R. Skifton, L. Hone, A.M. Casella, M. Prowant, M. Good, C. Hutchinson, T. Roosendaal, R. Montgomery, "Integration Testing of Ultrasonic Deformation Sensor for TREAT Experiments," INL/EXT-19-54981, 2019.

13. D. Ensminger and L. J. Bond, Ultrasonics: Fundamentals, Technologies, and Applications, 3rd ed.: CRC Press, 2012.

14. P. Ramuhalli, R. V. Harris, et al., "In-situ Characterization of Cast Stainless Steel (CASS) Microstructures," ed. Berlin, Germany, 2010.

15. M. R. Larche et al, "Progress in the development and demonstration of a 2D-matrix phased array ultrasonic probe for under-sodium viewing," AIP Conf. Proc., Vol. 1706, Issue 1, 2016.

16. D. R. Weier, and A. F. Pardini, Evaluation of UT Wall Thickness Measurements and Measurement Methodology, Technical Report, Pacific Northwest National Laboratory, PNNL16828 , Oct 2007.

17. L. C. Lynnworth, Ultrasonic Measurements for Process Control: Theory, Techniques, Applications: Elsevier Science, 2013.

18. S. R. Doctor, "Nuclear Power Plant NDE Challenges - Past, Present, and Future," presented at the Review of Progress in Quantitative Nondestructive Evaluation, Portland, Oregon, 2007.

19. D. Baron, D. Laux, and G. Despaux, "Mechanical characterisation of irradiated fuel materials with local ultrasonic methods," in Pellet-clad Interaction in Water Reactor Fuels, 2004.

20. Prowant M, G Dib, H Qiao, M Good, M Larche, S Sexton and P Ramuhalli. 2017. "Preliminary Design of High Temperature Ultrasonic Transducers for Liquid Sodium Environments." In Review of Progress in Quantitative Nondestructive Evaluation, Provo, UT. 
21. "FUTURE Transient Testing of Advanced Fuels," Summary of the May 4-5, 2009 Transient Testing Workshop Held at Idaho National Laboratory, 2009.

22. "TREAT Baseline Description Document," ANL/RAS 72-23, Aug., 1972.

23. N. Woolstenhulme, C. Baker, J. Bess, D. Chapman, C. Jensen, C. Hill, D. Wachs, S. Wilson, "Status Report for NEET In-Pile Sensor Irradiation Capabilities at TREAT," INL/EXT-17-43274, Sept., 2017.

24. N.E. Woolstenhulme, "Update on TREAT Restart and Experimental Design Preparations," OSU IRP Meeting November 2017, Corvallis, WA.

25. Dan Wachs, "Status of Transient Testing Capabilities in the United States," GAIN Workshop on Fuel Safety Research, Idaho Falls, ID, May1-5, 2017.

26. J. Daw, A. Crawford, R. Skifton, L. Hone, P. Ramuhalli, R.E. Jacob, A.M. Casella, R.O. Montgomery, "Design Requirements for Ultrasonic Deformation Sensor for TREAT Experiments," INL/EXT-18-45209, 2018.

27. P. Ramuhalli, M.S. Good, R.E. Jacob and J. Daw, "Preliminary Assessment of Sensor Materials for TREAT Ultrasonic Dimension Sensor," PNNL-27727, 2018.

28. P. Ramuhalli, R.E. Jacob, R.O. Montgomery, M. Prowant, M.S. Good, J. Daw, "Preliminary Sensor Design Concepts for Ultrasonic Dimensional Measurements," PNNL-28092, 2018. 